\title{
Neurotrophin-3 and Brain-Derived Neurotrophic Factor Induce Oligodendrocyte Proliferation and Myelination of Regenerating Axons in the Contused Adult Rat Spinal Cord
}

\author{
Dana M. McTigue1, Philip J. Horner², Bradford T. Stokes ${ }^{1}$, and Fred H. Gage ${ }^{2}$ \\ ${ }^{1}$ Department of Physiology, Ohio State University, Columbus, Ohio 43210, and '2Laboratory of Genetics, The Salk \\ Institute, La Jolla, California 92161
}

Functional loss after spinal cord injury (SCl) is caused, in part, by demyelination of axons surviving the trauma. Neurotrophins have been shown to induce oligodendrogliagenesis in vitro, but stimulation of oligodendrocyte proliferation and myelination by these factors in vivo has not been examined. We sought to determine whether neurotrophins can induce the formation of new oligodendrocytes and myelination of regenerating axons after $\mathrm{SCl}$ in adult rats. In this study, fibroblasts producing neurotrophin-3 (NT-3), brain-derived neurotrophic factor (BDNF), ciliary neurotrophic factor, nerve growth factor, basic fibroblast growth factor, or $\beta$-galactosidase (control grafts) were transplanted subacutely into the contused adult rat spinal cord. At 10 weeks after injury, all transplants contained axons. NT-3 and BDNF grafts, however, contained significantly more axons than control or other growth factor-producing grafts. In addition, significantly more myelin basic protein-positive profiles were detected in NT-3 and BDNF transplants, suggesting en-

Axonal demyelination is a consistent pathological characteristic of the traumatically injured spinal cord (Gledhill et al., 1973; Bresnahan, 1976; Balentine, 1978; Blight, 1983). Unfortunately, extensive remyelination does not occur spontaneously. This may be caused, at least in part, by loss of oligodendrocytes by apoptotic death (Li et al., 1996; Crowe et al., 1997) and a subsequent lack of oligodendrocyte proliferation to replace the lost cells. Preliminary data from the normal adult rat spinal cord have demonstrated cellular proliferation leading to the formation of new oligodendrocytes, particularly in lateral white matter tracts (Horner et al., 1997). Because it is thought that oligodendrocyte division is a prerequisite of the myelination process (for review, see Vick et al., 1992b), the ability to upregulate this endogenous proliferation of oligodendrocytes or, more likely, their precursors, after spinal cord injury (SCI) may be an important mechanism for myelin repair.

Several studies have indicated that cells of the oligodendrocyte

Received Feb. 25, 1998; revised April 28, 1998; received May 4, 1998.

These studies were supported by the American Paralysis Association, Grants NS 10165 and NS 33696, the Hollfelder Foundation, and the Bremer Foundation. The Rip antibody developed by B. Friedman, S. Hockfield, J. Black, K. Woodruff, and S. Waxman was obtained from the Developmental Studies Hybridoma Bank maintained by the University of Iowa, Department of Biological Sciences, Iowa City, IA 52242, under contract NO1-HD-7-3263 from the NICHD. We thank Dr. Phillip Popovich and Dr. Lyn Jakeman for critically reading this manuscript, and Patricia Walters, Ping Wei, Zhen Guan, and Yifei Chen for expert technical assistance.

Correspondence should be addressed to Dr. Bradford T. Stokes, College of Medicine and Public Health, 228 Meiling Hall, 370 W. 9th Avenue, Columbus, OH 43210.

Copyright (ㄷ) 1998 Society for Neuroscience $\quad 0270-6474 / 98 / 185354-12 \$ 05.00 / 0$ hanced myelination of ingrowing axons within these neurotrophin-producing grafts. To determine whether augmented myelinogenesis was associated with increased proliferation of oligodendrocyte lineage cells, bromodeoxyuridine (BrdU) was used to label dividing cells. NT-3 and BDNF grafts contained significantly more BrdU-positive oligodendrocytes than controls. The association of these new oligodendrocytes with ingrowing myelinated axons suggests that NT-3- and BDNF-induced myelinogenesis resulted, at least in part, from expansion of oligodendrocyte lineage cells, most likely the endogenous oligodendrocyte progenitors. These findings may have significant implications for chronic demyelinating diseases or CNS injuries.

Key words: spinal cord injury; axonal regeneration; transplantation; neurotrophins; oligodendrocyte proliferation; progenitor; Schwann cells lineage may be targeted by various growth factors. For instance, basic fibroblast growth factor (bFGF)-induced proliferation and migration has been demonstrated in mature oligodendrocytes and their progenitors (Fressinaud et al., 1995; Engel and Wolswijk, 1996; McMorris and McKinnon, 1996; Bansal and Pfeiffer, 1997). In addition, the expression of functional tyrosine kinase $\mathrm{A}$ (trkA), trkB, and trkC receptors on oligodendrocytes and their progenitors indicates that a direct action of neurotrophins on these cells may be possible (Barres et al., 1994; Condorelli et al., 1995; Cohen et al., 1996; Kumar and de Vellis, 1996). Indeed, the survival of purified mature oligodendrocytes in culture was enhanced by neurotrophin-3 (NT-3) or, to a lesser degree, ciliary neurotrophic factor (CNTF) in the absence of other growth factors (Barres et al., 1993). NT-3, in the presence of insulin, also promoted the incorporation of bromodeoxyuridine (BrdU) into purified oligodendrocyte precursors (Barres et al., 1993), suggesting that precursor proliferation could be stimulated by this neurotrophin. Thus, in addition to their well known neuroprotective and regenerative effects, neurotrophic factors also may enhance oligodendrocyte survival and proliferation, possibly in association with improved myelination or remyelination.

In the present study, we transplanted fibroblasts engineered to produce specific growth factors into the contused adult rat spinal cord. These grafts provided an in vivo opportunity for examining neurotrophin-mediated effects on axonal ingrowth, proliferation of oligodendrocyte lineage cells, and myelination of newly growing axons. In control (non-growth factor-producing) transplants, 

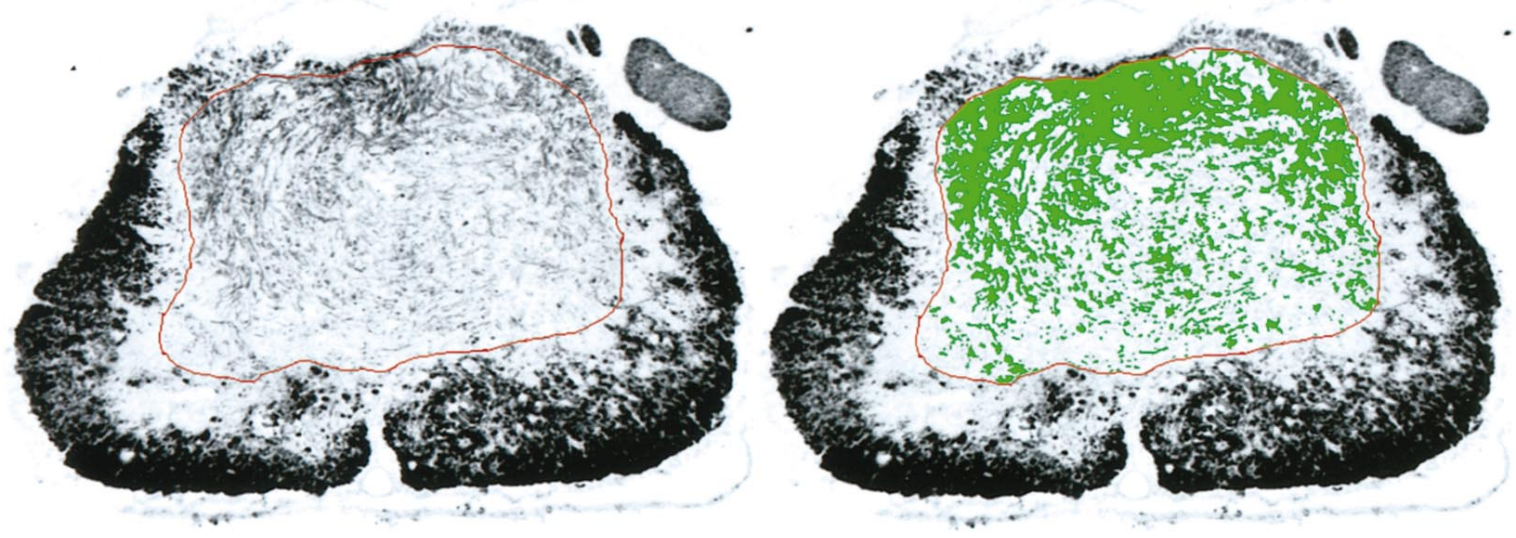

Figure 1. Illustration of proportional area measurements. Images are from a cross section of an NT-3 graft that was immunohistochemically labeled for MBP. The left image shows the digitized spinal cord; the graft border has been manually outlined in red. The area inside the red border, i.e., the cross-sectional graft area, corresponds to the scan area. The right image demonstrates the MBP-ir profiles within the graft that were selected as positive ( green); these correspond to the target area. Proportional area was calculated by dividing the target area by the scan area.

axon ingrowth was significantly greater than that observed in the lesion site of nongraft recipients, suggesting that the fibroblasts provided a growth-supportive matrix for regenerating and/or sprouting axons. We found that of the growth factors produced by the fibroblast grafts, only NT-3 and brain-derived neurotrophic factor (BDNF) induced significantly more ingrowth of host axons than control grafts. NT-3 and BDNF grafts also contained significantly more myelin profiles, indicating that myelination of the ingrowing axons was the greatest in these grafts. Last, newly formed oligodendrocytes were seen in significantly higher numbers in NT-3 and BDNF grafts compared with control grafts, suggesting that proliferation of oligodendrocyte lineage cells was promoted in these spinal cords.

\section{MATERIALS AND METHODS}

Spinal cord injury (SCI) and transplantation of fibroblasts. Adult female Fisher 344 rats $(150-175 \mathrm{~g})$ were anesthetized with ketamine $(0.8 \mathrm{mg} / \mathrm{kg}$, i.p.) and xylazine $(0.5 \mathrm{mg} / \mathrm{kg}$, i.p.). A dorsal laminectomy was performed at the eighth thoracic vertebrae, and the $\mathrm{T}_{7}$ and $\mathrm{T}_{9}$ spinous processes were rigidly fixed in a spinal frame. Rats then received a closed-dural contusion injury using the Ohio State injury device, which involved rapid displacement of the dorsal spinal cord $0.9 \mathrm{~mm}$ for $23 \mathrm{msec}$ as described previously (Anderson and Stokes, 1992; Stokes et al., 1992, 1995). Afterward, skin and muscle layers were closed and incisions were covered with antibiotic. Animals were allowed to recover from anesthesia in warmed cages.

For transplantation, cultured Fisher 344 fibroblast cells engineered to produce $\beta$-galactosidase ( $\beta$-gal), NT-3, BDNF, CNTF, bFGF, or NGF (Kawaja and Gage, 1992; Senut et al., 1995) were isolated and suspended in $0.6 \%$ glucose-PBS to a final concentration of $0.4 \times 10^{6}$ cells $/ \mu \mathrm{l}$. At $2 \mathrm{~d}$ after injury, rats were anesthetized as above; the laminectomy site was reexposed, and $5 \mu \mathrm{l}$ of the cell suspension was injected directly into the lesion site $[\beta$-gal $(n=6), \mathrm{NT}-3(n=6), \operatorname{BDNF}(n=12), \operatorname{CNTF}(n=5)$, bFGF $(n=5)$, or NGF $(n=5)]$. Rats serving as injury controls underwent the same surgical procedure of spinal cord reexposure but received no intraspinal injection $(n=11)$. Incisions were closed as above, and animals were allowed to recover from anesthesia.

Viability of the fibroblasts, determined at the conclusion of transplantation each day, was $\geq 90 \%$. Animals were allowed to survive for 10 weeks after injury, at which time they were deeply anesthetized and perfused through the left ventricle with PBS followed by $4 \%$ paraformaldehyde.

Immunohistochemistry. To label dividing cells in $\beta$-gal-, NT-3-, or BDNF-graft recipients, rats received daily injections of BrdU [(Sigma, St. Louis) $50 \mathrm{mg} / \mathrm{kg}$, i.p.] for $7 \mathrm{~d}$ beginning at day 21 after injury. At 10 weeks after injury, spinal cords were removed from perfused rats, frozen in OCT compound, cut on a cryostat at $20 \mu \mathrm{m}$, and slide-mounted. For protocols using DAB as the chromagen [neurofilament and myelin basic protein (MBP)], sections were blocked in $10 \%$ serum/PBS with $0.1 \%$ Triton X-100 to reduce nonspecific staining and then incubated with primary antibody overnight at $4^{\circ} \mathrm{C}$. On the following day, sections were rinsed with PBS, and secondary antibody (1:400) was applied for $1 \mathrm{hr}$ at room temperature. The sections then were incubated in $\mathrm{ABC}$ compound (Vector Laboratories, Burlingame, CA) followed by DAB, dehydrated, and coverslipped. For fluorescent labeling of BrdU, sections were pretreated by incubation for $1 \mathrm{hr}$ in $50 \%$ formamide/ $2 \times$ saturated sodium citrate at $65^{\circ} \mathrm{C}$ followed by a $30 \mathrm{~min}$ wash in $2 \mathrm{~N} \mathrm{HCl}$ at $37^{\circ} \mathrm{C}$. For $\mathrm{BrdU}$ and all other antibodies (S100 $\beta$, RIP, neurofilament, MBP, P0), sections were then rinsed in buffer and nonspecific staining was blocked as above. Primary antibodies directed against BrdU (1:100; Harlan, Indianapolis, IN), RIP (1:100; Developmental Studies Hybridoma Bank), S100 $\beta$ (1: 10,000: S Want), neurofilament (1:50; RT97, Boehringer Mannheim, Indianapolis, IN), MBP (monoclonal at 1:500, Sternberger Monoclonals, Baltimore, MD; or polyclonal at 1:50, Chemicon International, Temecula, CA), P0 (1:2000; generous gift of Dr. Juan Archelos, Universität Würzburg, Germany), choline acetyltransferase (ChAT; 1:500; Chemicon), serotonin (1:2500, Eugene Tech International, Ridgefield Park, $\mathrm{NJ}$ ), calcitonin gene-related peptide (CGRP; 1:1000; Chemicon), or tyrosine hydroxylase (TH; 1:1000; Boehringer Mannheim) were applied to sections alone or in combination and allowed to incubate overnight at $4^{\circ} \mathrm{C}$. After sections were rinsed with buffer on the following day, fluorescently conjugated secondary antibodies (Texas Red, Cy5, or FITC; 1:250; Jackson ImmunoResearch Laboratories, West Grove, PA) were applied for $1 \mathrm{hr}$, after which the sections were rinsed and coverslipped.

Proportional area measurements. To quantify neurofilament- or MBPimmunoreactive (ir) fibers within the grafts, sampling techniques were modified from those used previously in injured rat spinal cord tissue (Popovich et al., 1997). Briefly, two to three cross sections containing the lesion epicenter were selected from each rat and analyzed in a blinded fashion. Using computer-assisted image analysis (MCID M4; Imaging Research, Ontario), sections were digitized at $5 \times$, and the graft borders were outlined manually (Fig. 1). Digitized sections were contrastenhanced to clearly facilitate recognition of all neurofilament- or MBPpositive profiles. Measurements were made of the scan area (total crosssectional area of graft), target area within the graft (profiles immunopositive for neurofilament or MBP), and proportional area (target area divided by scan area). An example of these measurements is depicted in Figure 1. Because the segmentation range can be adjusted manually so that all positive myelin profiles (or axons) within the grafts are equally represented, differences in staining intensity between sections were not a factor in the present analysis. Proportional areas for each group were compared using one-way ANOVA followed by a Bonferroni multiple comparisons test to determine whether the growth factors differentially affected axonal ingrowth or myelination.

Cell counting protocol. The total number of BrdU-ir nuclei was counted in $0.0326 \mathrm{~mm}^{2}$ measuring frames $(63 \times)$ by a blinded observer. Az-series was collected by optically sectioning three to five random sections $(0.012$ 
mm section thickness) within transplants from $\beta$-gal $(n=5)$, NT-3 $(n=$ $5)$, or BDNF $(n=4)$ graft recipients. The first optical section from each series was discarded (Gundersen et al., 1988). The number of BrdU nuclei, BrdU/RIP-positive cells, and BrdU/S100 $\beta$-positive cells was counted in each frame. Only BrdU-ir nuclei that were completely surrounded by RIP or $\mathrm{S} 100 \beta$ immunoreactivity were counted as doublelabeled. These counts provided an indication of the number of oligodendrocytes (RIP) and astrocytes or Schwann cells (S100 $\beta$ ) within the grafts that arose from mitotically active cells. However, because of the time elapsed between BrdU application and the time the rats were killed, i.e., 6 weeks, cell counts may actually underestimate the number of cycling cells because of dilution of BrdU signal after repeated cellular division. Thus, BrdU-positive cells seen at 10 weeks after injury most likely left the cell cycle soon after mitotic labeling. The density of BrdU-positive cells within the grafts was calculated by dividing the number of counted cells by the volume of the measured area, which was $0.00039 \mathrm{~mm}^{3}$ (surface area $\times$ section thickness). Densities were compared between the groups with a one-way ANOVA followed by a Bonferroni multiplecomparisons test.

\section{RESULTS}

\section{Fibroblast grafts fill the lesion cavities produced by spinal cord contusion}

The present study used a reproducible and clinically relevant model of spinal contusion injury. After injury, the solid neuropil (Fig. 2A) evolves into a central cystic cavitation at the lesion epicenter, with a surrounding rim of surviving axons (Figs. $2 C$, $3 A$ ). This chronic lesion morphology is similar to that often seen in human spinal cords after trauma (Kakulas, 1984). At the time of transplantation, i.e., $2 \mathrm{~d}$ after injury, there is already a drastic reduction in the amount of axons present at the lesion site (Fig. $2 B$ ). Over time, however, axon growth as a result of sprouting and/or regeneration occurs at the epicenter, particularly along the borders of cystic cavities (Fig. 2C). Thus, a limited amount of endogenous regrowth occurs in the epicenter of the injured spinal cord (Guth et al., 1985; Beattie et al., 1997).

As seen in Figure $3 B, C$, fibroblast grafts filled the lesion cavities. The fibroblasts survived chronically within the injured spinal cord and did not migrate out of the graft into the host parenchyma. Immunohistochemistry for $\beta$-galactosidase revealed that expression of the transgene was still evident at the time the rats were killed, i.e., 10 weeks after transplantation (data not shown), indicating long-term gene expression by the fibroblasts in the contused spinal cord.

\section{NT-3 and BDNF stimulate axon growth into the grafts}

At 10 weeks after injury, axons were present to differing degrees within all fibroblast grafts. Indeed most grafts, including $\beta$-gal controls, displayed significantly greater axon ingrowth than that seen in the lesion epicenter of nongraft recipients $(p<0.001)$ (Fig. 3D). This suggests that neuritogenesis at the lesion site can be enhanced by the presence of a growth-permissive substrate.

The extent of axon growth into and within the grafts was influenced by growth factor expression. NT-3- and BDNFproducing grafts contained significantly more neurofilamentlabeled axons than $\beta$-gal, NGF, CNTF, or bFGF grafts $(p<$ 0.001) (Fig. $3 B-D$ ). Thus, compared with controls, only BDNF and NT-3 further stimulated the axon growth into the grafts occurring at the epicenter.

Immunohistochemical results indicate that several fiber phenotypes extended into the transplants. Peripheral axons, labeled as CGRP-ir profiles (Fig. 4A), displayed extensive sprouting after injury alone. These fibers typically were associated with the cystic cavity/dorsal white matter interface (Fig. 4B). The fibers, however, never crossed the cyst and were rarely seen in the lateral white matter at the epicenter. In the presence of control ( $\beta$-gal) fibroblast grafts, CGRP-ir fibers extended throughout the entire rostral to caudal portions of the grafts. Compared with $\beta$-gal grafts, CGRP axonal ingrowth was elevated in all growth factorproducing grafts (Fig. 4C), suggesting that these fibers may respond nonspecifically to various growth factors.

The cholinergic spinal motor neurons and their projections can be labeled immunohistochemically with ChAT antibodies (Fig. $4 D)$. After SCI alone, sprouting of motor neuron axons was not detected within the injury site. Furthermore, ChAT-ir cells in the ventral gray matter caudal to the injury site appeared to have lost many of their processes (Fig. 4D,E). Unlike CGRP fibers, ChAT-ir axons did not extend into control grafts (Fig. $4 F$ ) or grafts producing NGF, CNTF, or bFGF. However, NT-3 and BDNF both promoted extensive ChAT-ir fiber growth into the graft parenchyma (Fig. 4G).

Finally, supraspinal fibers also projected into the grafts. Serotonin-ir (Fig. 4H-J) and TH-ir (data not shown) axons were detected within all grafts examined. Interestingly, only modest extension of serotonin fibers into fibroblast grafts was seen, with more robust growth found in the lateral white matter just outside the grafts.

\section{Myelination of axons was greatest in NT-3 and BDNF grafts}

Because axons are presumed to be unmyelinated as they grow into the grafts, this model provided a unique system for examining the effect of growth factors on myelination of growing axons. Double-label immunofluorescence for MBP and neurofilament was used to visualize myelinated axons within $\beta$-gal grafts and growth factor grafts containing a high (NT-3) or low (bFGF) density of neurofilament-positive profiles (see above). Although control and bFGF-producing grafts contained axons, few were ensheathed with MBP, indicating that a low proportion of these growing fibers became myelinated (Fig. $5 A, B, D, E$ ). In contrast, nearly all the axons within NT-3-producing grafts were surrounded by MBP immunoreactivity (Fig. 5C,F). Confocal imaging of the NT-3 graft clearly revealed that neurofilament-ir axons were surrounded by MBP immunoreactivity (Fig. 5G). These results suggest that the presence of bare axons alone does not necessarily result in the formation of new myelin.

Quantitation of the proportional area of the grafts occupied by MBP (Fig. 1) revealed that NT-3, BDNF, CNTF, and $\beta$-gal grafts contained a significantly greater amount of MBP-ir profiles than the lesion site of injury control spinal cords $(p<0.001)$ (Fig. $6)$. This suggests that fibroblast grafts are not only growth permissive for growing neurites, but they also provide an environment that is conducive for myelination of these ingrowing axons. As with neurofilament, NT-3- and BDNF-producing grafts also contained significantly more MBP-ir profiles than the other growth factor-producing grafts $(p<0.001)$ (Fig. 6). On the basis of the above double-label immunohistochemistry, these profiles most likely represent myelinated axons.

\section{Myelination of axons in grafts arises from oligodendrocytes and Schwann cells}

Because Schwann cells may contribute to the myelination observed in the injured spinal cord, their distribution within the grafts was compared with that of oligodendrocytes, with antibodies specific for each cell type, i.e., P0 for Schwann cell myelin (Archelos et al., 1993) and RIP for oligodendrocytes (Friedman et al., 1989). Although both oligodendrocyte- and Schwann cell- 

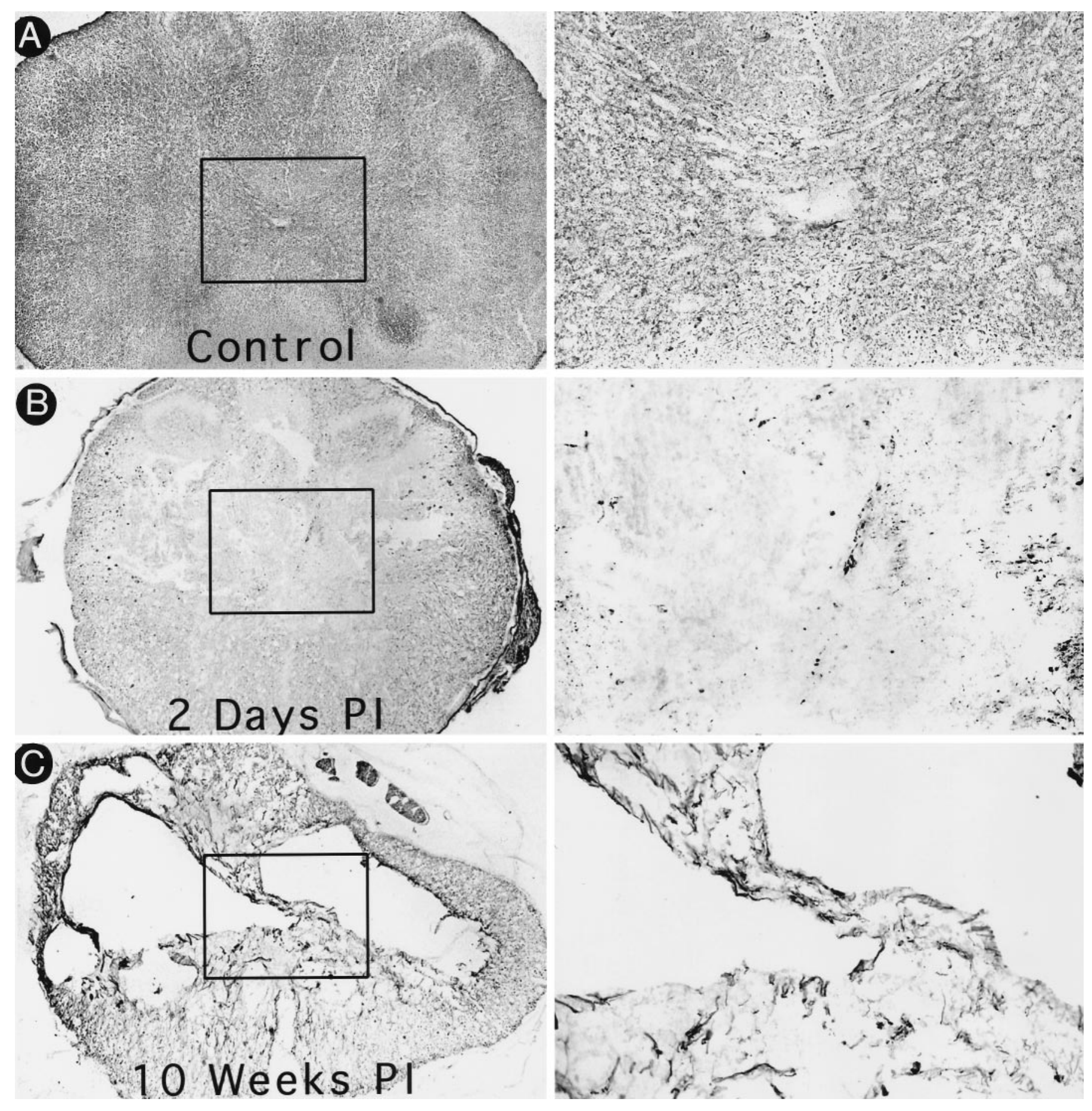

Figure 2. Neurofilament-ir in a normal, $2 \mathrm{~d}$ post-injury (PI) and 10 week PI spinal cord. Comparison of neurofilament-ir at $\mathrm{T}_{8}$ from a normal spinal cord $(A, 5 \times)$ and a spinal cord epicenter at 2 Days $P I(B, 5 \times)$ reveals the minimal amount of axons spared in the epicenter at the time of transplantation. By 10 Weeks PI $(C, 5 \times)$, there was an increase in the number of axons observed in the epicenter compared with that seen at 2 Days PI, suggesting that a limited amount of endogenous regrowth occurred at the injury site. The black boxes in $A-C$ are shown at higher power (40×) to the right of each image.

derived myelin were detected in the grafts, their relative magnitudes were dependent on the growth factor produced. NGF, $\mathrm{CNTF}$, and $\beta$-gal grafts contained approximately equal amounts of oligodendrocyte and Schwann cell myelin (Fig. 7). Interestingly, more Schwann cell myelin than that of oligodendrocytes was noted within bFGF grafts, whereas P0 labeling was nearly absent in the surrounding host tissue; this may suggest a chemotropic action of bFGF on Schwann cells and also may account for the low amount of MBP-ir in these grafts (Fig. 5). Grafts producing NT-3 or BDNF clearly contained a greater amount of oligodendrocyte-derived myelin profiles than $\mathrm{P} 0$-ir myelin (Fig. 7). This indicates that oligodendrocytes were primarily responsible for the myelinogenesis stimulated by the NT-3 and BDNF grafts. Thus, it is likely that NT-3 and BDNF recruited more oligodendrocytes into the graft environment than the other growth factors tested. 


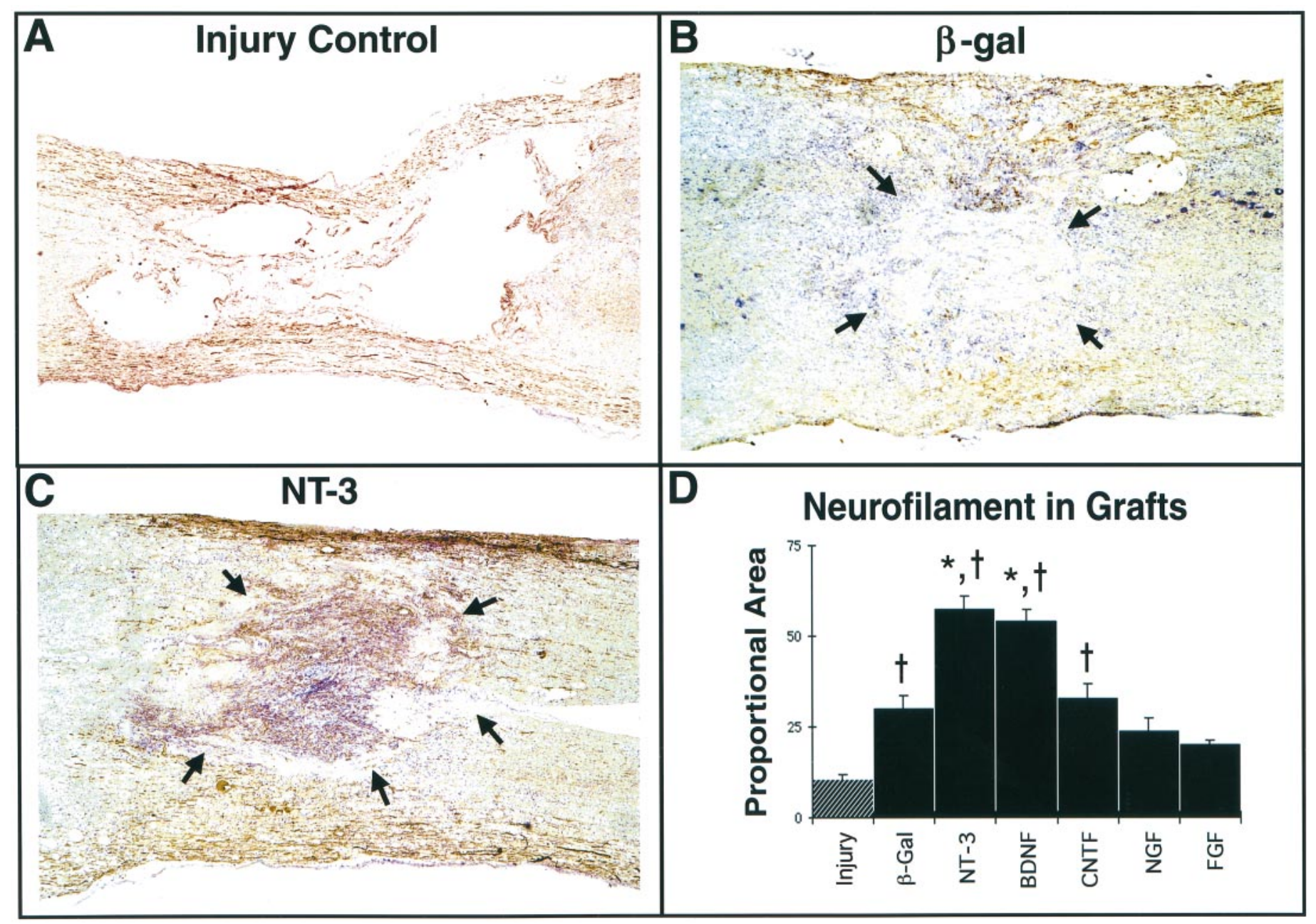

Figure 3. Comparison of neurofilaments in injury control and transplanted spinal cords. Horizontal sections from an injured spinal cord (nongraft recipient) $(A)$, a $\beta$-gal graft $(B)$, and an NT-3-producing graft $(C)$ immunolabeled for neurofilament and counterstained with cresyl violet. Images are from rats that received grafts at $10 \mathrm{~d}$ after injury and survived for 12 weeks. They are representative, however, of spinal cords from $2 \mathrm{~d}$ post-injury transplants and 10 week survival times. Arrows in $B$ and $C$ delineate graft perimeters. Note that grafts filled the lesion cavities and that NT-3 production increased the amount of axons extending into the grafts. Quantitation of the proportional area of the grafts occupied by neurofilaments $(D)$ revealed that NT-3, BDNF, CNTF, and $\beta$-gal grafts contained significantly more axons than the lesion epicenter and nongraft recipients ( ${ }^{\dagger} p<0.05$ for $\beta$-gal and CNTF, and $p<0.001$ for NT-3 and BDNF). In addition, BDNF and NT-3 stimulated a more robust infiltration of axons in comparison with $\beta$-gal or other growth factor grafts $\left({ }^{*} p<0.01\right)$. (Bars represent mean $\pm \mathrm{SEM} ; n=5$ for injury control, NGF, CNTF, FGF; $n=6$ for $\beta$-gal, NT-3; $n=11$ for BDNF).

\section{Proliferation of oligodendrocyte lineage cells was stimulated by NT-3 and BDNF grafts}

A possible explanation for the elevated number of oligodendrocytes and myelinated profiles in NT-3 and BDNF grafts is neurotrophin-induced proliferation of oligodendrocyte lineage cells. These may include dividing oligodendrocyte progenitors that differentiate into mature cells or, less likely, cycling mature oligodendrocytes. To determine the number of new oligodendrocytes within the fibroblast grafts, BrdU was administered during the fourth week after injury to label dividing cells in rats that had received $\beta$-gal, NT-3, or BDNF grafts. Six weeks later, immunohistochemistry for BrdU revealed that new cells within $\beta$-gal grafts were relatively sparse, whereas significantly greater numbers of cells that had undergone mitosis were present in BDNFand NT-3-expressing grafts (Fig. 8A). To determine the fate of the dividing cells, triple-labeling for BrdU, RIP (oligodendrocytes), and $\mathrm{S} 100 \beta$ (astrocytes/Schwann cells) was used. An example of three RIP-positive oligodendrocytes with BrdU-positive nuclei is shown in Figure $8 B$.
Quantification of the total number of BrdU-ir cells revealed that NT-3 grafts contained significantly more new cells than $\beta$-gal $(p<0.001)$ or BDNF grafts $(p<0.05)$ (Fig. 9A). BDNFproducing grafts, however, also contained more BrdU-ir cells than control grafts $(p<0.001)$. Thus, cellular proliferation in general was greater in the neurotrophin grafts. The number of new oligodendrocytes (BrdU and RIP co-labeled) within the grafts was significantly greater in NT-3 $\left(3.1 \times 10^{4} \mathrm{cells} / \mathrm{mm}^{3}\right)$ and BDNF $\left(3.0 \times 10^{4}\right.$ cells $\left./ \mathrm{mm}^{3}\right)$ grafts compared with $\beta$-gal grafts $\left(0.6 \times 10^{4}\right.$ cells $\left./ \mathrm{mm}^{3} ; p<0.01\right)$ (Fig. $\left.9 B\right)$. These cells typically were associated with myelin profiles, most likely representing myelinated axons (Fig. 5C,F). In contrast to oligodendrocytes, the number of astrocytes or Schwann cells proliferating at the time of BrudU injections was much lower and did not differ between the groups (Fig. 9C), suggesting that the effect of the neurotrophins on oligodendrocyte lineage cell mitosis was specific. Other BrdUlabeled cells not phenotypically identified with the above markers (Fig. 9D) may represent unlabeled oligodendrocyte progenitors or turnover in the fibroblast population. 


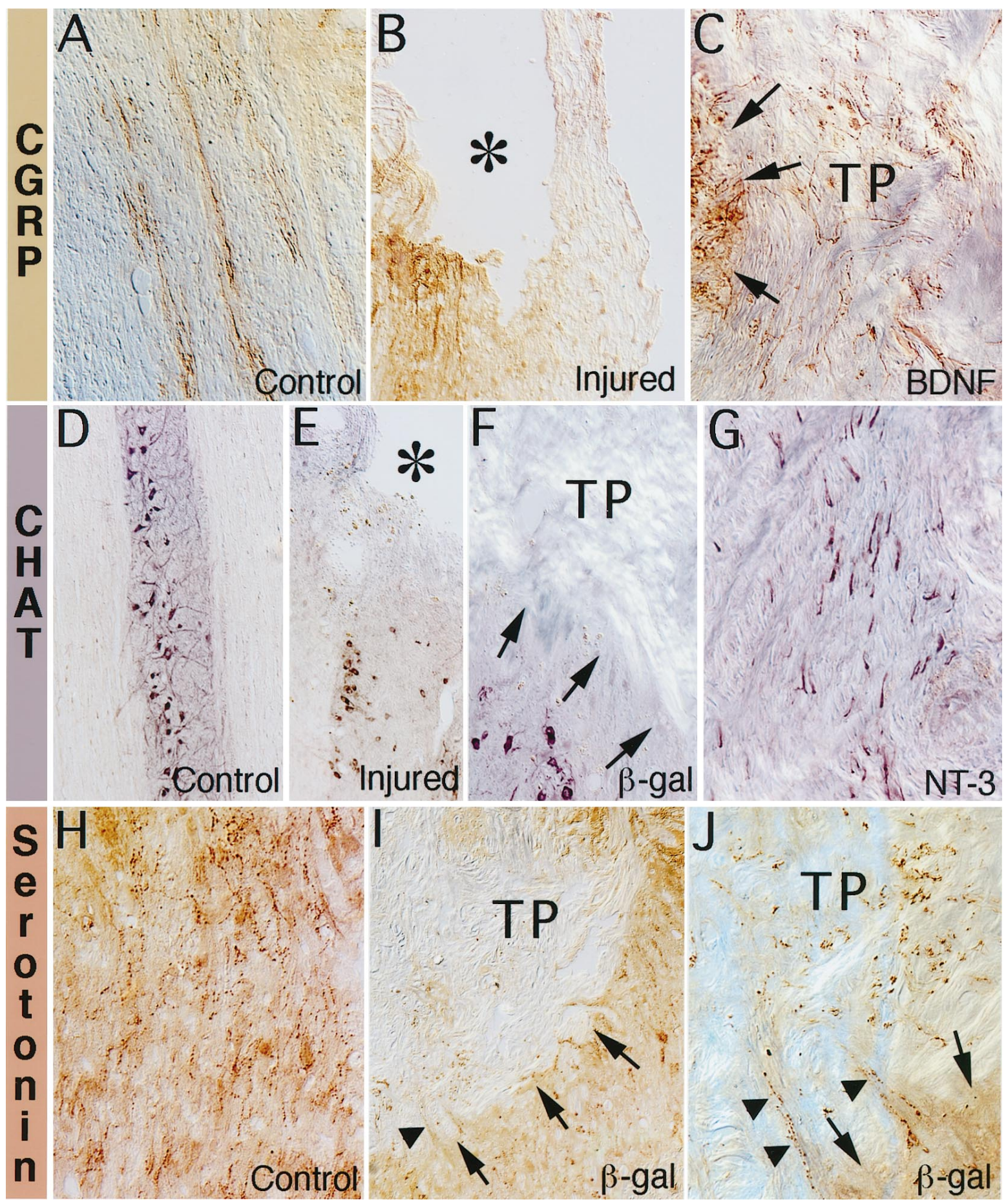

Figure 4. Immunocytochemical identification of several fiber phenotypes within the grafts. $C G R P$, Horizontal sections of an uninjured spinal cord $(A$, $20 \times)$, an injured nongrafted spinal cord $(B, 20 \times)$, and a BDNF-producing graft $(C, 20 \times)$. In uninjured controls, CGRP-ir was restricted to the soma and axons of ventral horn motor neurons and small diameter axons in the dorsal white matter $(A)$. In the injured nongrafted animals, CGRP fibers were found in abundance in the dorsal aspect of the spinal cord near the lesion interface $(B)$. Asterisk indicates lesion cavity. In $\beta$-gal transplants, CGRP fibers were limited within the graft, even in dorsal regions where CGRP fibers were sprouting in response to the injury. As shown in $C$ (a $B D N F$ graft, $T P$ ), growth factor-producing grafts contained large numbers of small-diameter, CGRP-ir fibers. These fibers appeared to make up the majority of small-diameter axons in the dorsal regions of the grafts. Arrows indicate host/graft interface in $C$. CHAT, Horizontal sections labeled for ChAT-ir from a control, uninjured spinal cord $(D, 20 \times)$, an injured nongrafted spinal cord $(E, 10 \times)$, a $\beta$-gal transplant $(F, 20 \times)$, and an NT-3 graft $(G, 20 \times)$. Note the lack of fiber staining in the injured, nongrafted spinal cord in and around the lesion (E; asterisk indicates lesion cavity). Some neurons appeared to have decreased ChAT levels caudal to the lesion. Grafts producing $\beta$-gal did not stimulate sprouting of ChAT-ir axons either adjacent to or within the grafts $(F)$. Arrows indicate the interface between graft $(T P)$ and host in $F$. Large-caliber ChAT-ir fibers extended from the host tissue into NT-3 (and BDNF) grafts $(G)$. Serotonin (5-HT), Immunohistochemistry of a control uninjured spinal cord $(H, 20 \times)$ and a $\beta$-gal-producing fibroblast graft $(I, 10 \times$, and $J, 40 \times ; T P$ ). 5-HT staining was restricted to small-diameter, varicose fibers within the spinal gray matter. Sparse numbers of 5-HT axons were noted in all transplants, including $\beta$-gal controls. Arrows indicate the interface between graft and host; arrowheads denote fibers crossing the graft/host border. 

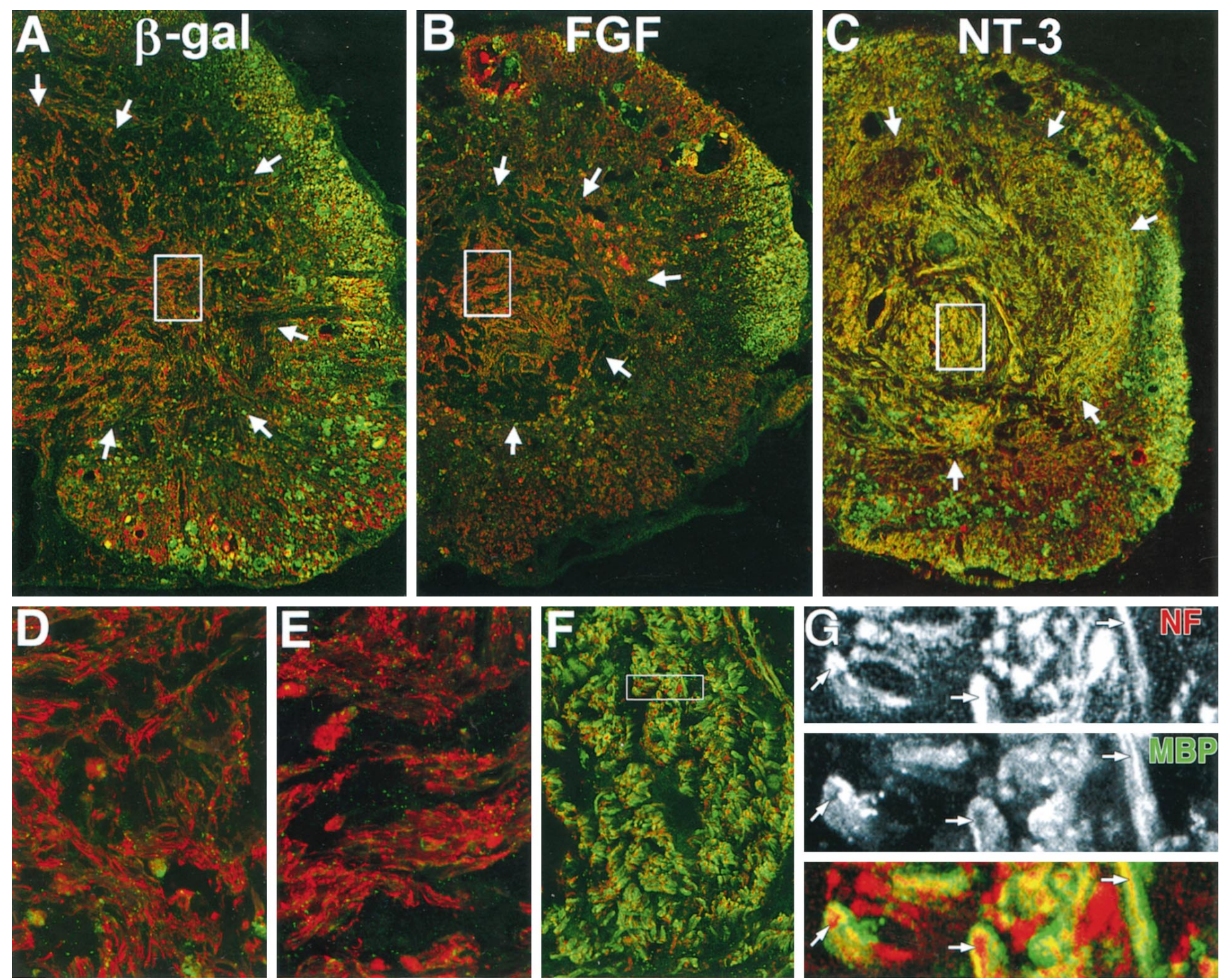

Figure 5. Neurofilament and MBP double-label immunohistochemistry. Coronal sections through epicenters from $\beta$-gal- $(A)$, bFGF- $(B)$, and NT-3-producing grafts $(C, 5 \times)$ that are double-labeled for neurofilament (red) and MBP ( green). White arrows delineate graft borders. Regions in white boxes are shown at high power $(40 \times)$ below $(D, E, F$, respectively). Note that neurofilament-positive axons extended into $\beta$-gal and bFGF grafts (although to a lesser degree than in NT-3 or BDNF grafts; see Fig. $3 D$ ). These fibers, however, were only occasionally myelinated. In addition, the outer rim of host white matter appeared dysmyelinated in spinal cords that received bFGF grafts. Fibers entering NT-3 grafts were almost entirely myelinated as seen by the extensive numbers of axons (red) surrounded by myelin (green). As seen in $G$ (enlargement of rectangle in $F$ ), neurofilament and MBP antibodies labeled separate entities $(120 \times)$. Axons (white arrows, top panel) and lumens of myelin sheaths (white arrows, middle panel) are easily visible. When these images are merged, it is clear that the axons (red) were surrounded by the myelin sheaths ( green).

\section{DISCUSSION}

In the present study, genetically engineered fibroblasts transplanted into the epicenter of SCI rats survived and successfully integrated with the host parenchyma. These grafts provided a growth-permissive and possibly growth-promoting terrain for axons, as indicated by the greater axon growth within these grafts, including $\beta$-gal control grafts, compared with that observed in the epicenter of nongraft recipients. Fibroblast grafts producing NT-3 or BDNF induced significantly more axonal ingrowth than grafts producing NGF, CNTF, bFGF, or $\beta$-gal. NT-3 and BDNF grafts also were the only grafts containing local ChAT-ir axons. This enhanced cholinergic fiber growth is consistent with other studies showing that injured spinal motor neurons display extensive growth in response to BDNF (Jakeman et al., 1997; Kishino et al., 1997; Novikov et al., 1997). Other axonal phenotypes, including serotonergic, TH-ergic, and CGRP-ergic fibers, were detected within all grafts, indicating that the fibroblasts provided a growth-permissive substrate for local, peripheral, and descending axons.

Both oligodendrocytes and myelinated axons were elevated within NT-3 and BDNF grafts, suggesting that these neurotrophins enhanced myelinogenesis by oligodendrocytes. A striking finding was the extent to which the formation of new oligodendrocytes was promoted by BDNF and NT-3 grafts. These new cells were observed throughout the grafts where, on the basis of their close association with myelinated axons, they contributed to the enhanced myelinogenesis. Collectively, these data indicate that neuritogenesis and myelination of growing axons in the adult injured CNS can be augmented by the presence of specific neurotrophins. 


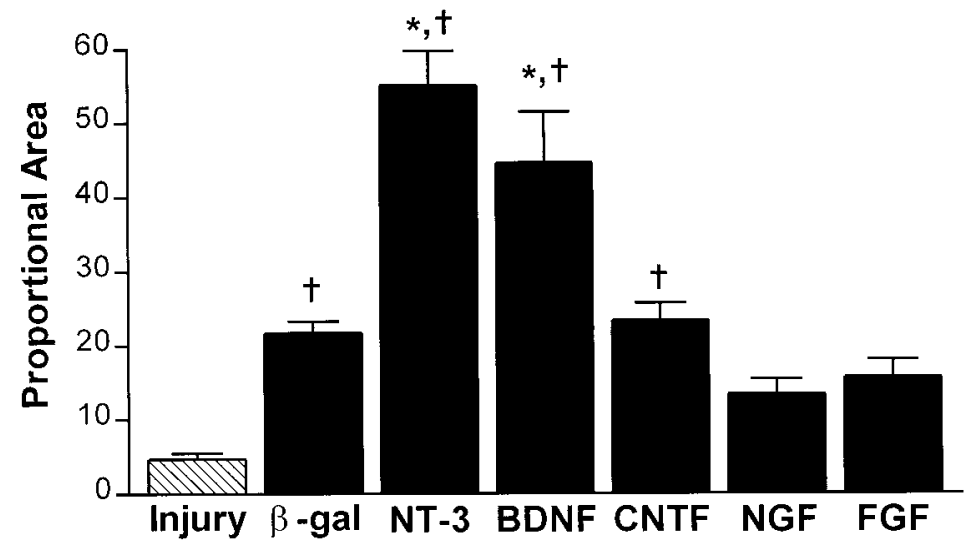

Figure 6. Quantitation of the cross-sectional area occupied by MBP-positive profiles within the grafts and lesion epicenter. Several of the grafts, including $\beta$-gal, NT-3, BDNF, and CNTF, contained significantly more myelinated profiles than that observed in the lesion site of nontransplanted rats (Injury; ${ }^{\dagger} p<0.001$ ). In addition, NT-3 and BDNF grafts contained significantly more MBP-positive fibers compared with all other grafts $\left({ }^{*} p<0.001\right)$. MBP expression within CNTF, FGF, and NGF grafts was not different from $\beta$-gal grafts. (Bars represent mean \pm SEM; $n=5$ for injury control, NGF, CNTF, FGF; $n=6$ for $\beta$-gal, NT-3; $n=11$ for BDNF).
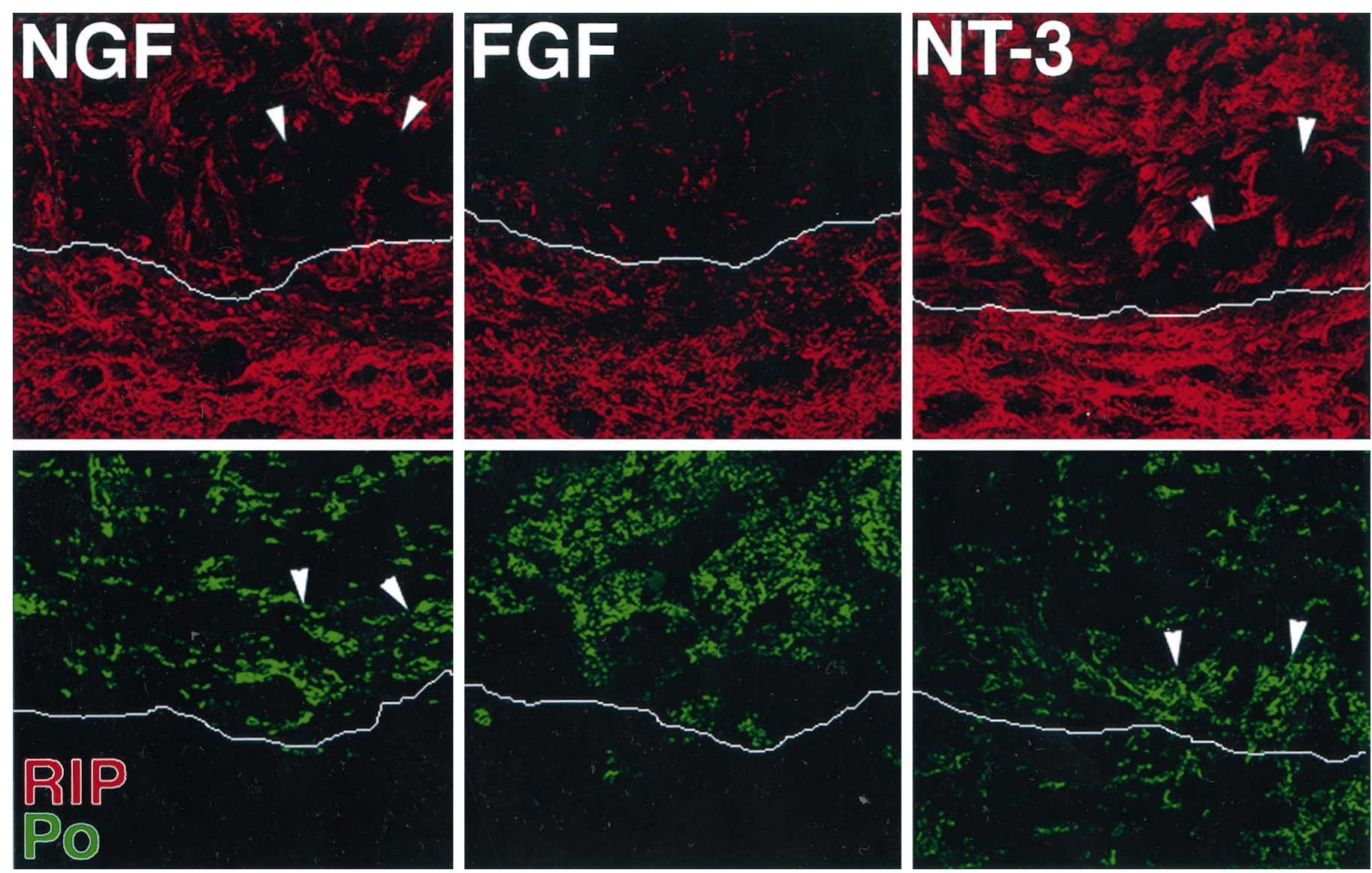

Figure 7. Comparison of Schwann cell and oligodendrocyte myelin within the grafts. Epicenter sections of an NGF-, bFGF-, or NT-3-producing graft at $70 \mathrm{~d}$ after injury $(20 \times)$. Adjacent sections were stained for oligodendrocytes and their myelin sheaths (RIP, red; top panels) or Schwann cell myelin $(\mathrm{P} 0$, green; bottom panels). White lines delineate the graft (above) from host ventrolateral white matter (below). Note that NGF grafts (and CNTF and $\beta$-gal grafts; data not shown) appeared to have similar amounts of RIP- and P0-ir myelin, whereas bFGF grafts had minimal RIP-positive myelin but extensive Schwann cell-derived myelin. NT-3 grafts and (BDNF grafts; data not shown) had numerous RIP-ir cells and myelin with much less P0-ir myelin. In adjacent sections, P0 and RIP did not appear to overlap (arrowheads).

These data extend previous findings that regeneration after SCI is possible when supportive matrices and/or appropriate growth factors are supplied (Xu et al., 1995; Cheng et al., 1996; Grill et al., 1997). Our results also provide an interesting contrast to those of Grill et al. (1997), in which axonal ingrowth into NT-3 grafts was not different from that in $\beta$-gal grafts placed into a spinal cord dorsal hemisection lesion. They, however, detected enhanced corticospinal growth ventral to NT-3 grafts, which again suggests growth-specific effects by NT-3.
The lack of a detectable effect by CNTF on myelination in the present study was somewhat surprising given the many reports of enhanced oligodendrocyte survival and proliferation by CNTF (Barres et al., 1993, 1996; Louis et al., 1993; D’Souza et al., 1996). Although the present study focused on transplant environment, it is possible that oligodendrocyte apoptosis in host white matter was altered by CNTF, an outcome measure not examined here.

The present results with bFGF grafts may be explained, at least in part, by previous in vitro work with FGF. For instance, bFGF 

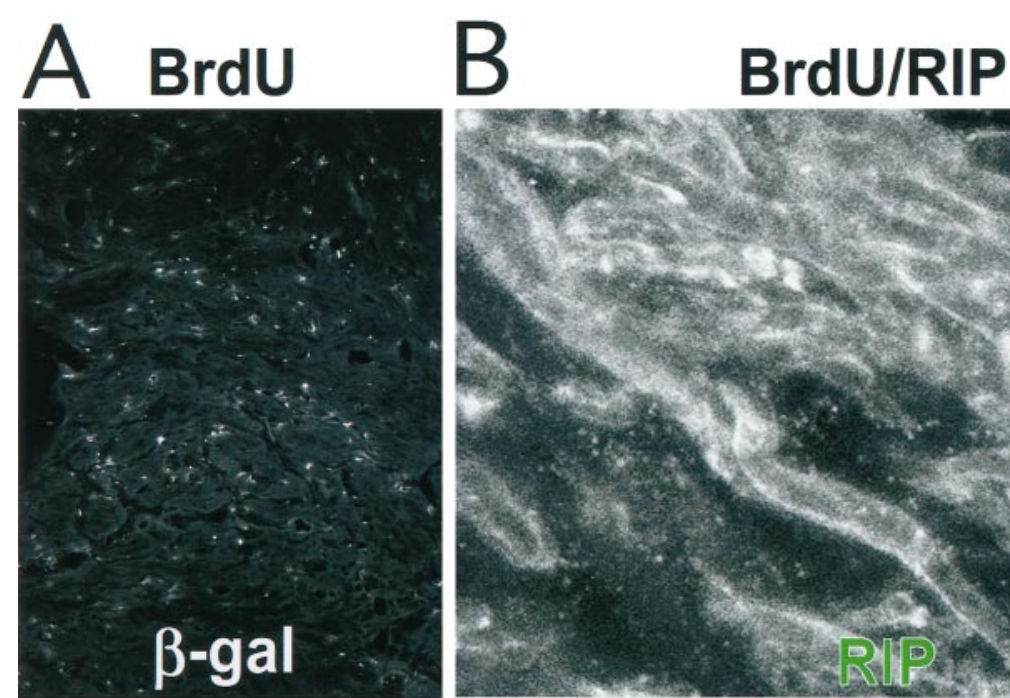

Figure 8. BrdU immunolabeling reveals increased numbers of mitotically active cells in general, and oligodendrocytes in particular, in NT-3 and BDNF grafts. $A$, Low-power photomicrographs $(10 \times)$ of BrdU-labeled cells within the designated grafts demonstrate that the relative number of dividing cells was increased in BDNF and NT-3 grafts. $B$, High-power photomicrograph $(320 \times)$ of an NT-3 graft demonstrates that many dividing cells (BrdU-positive) were double-labeled with RIP, revealing oligodendrocytes that were derived from cells that had undergone mitosis. When the RIP image is superimposed on the BrdU image, three BrdU-positive oligodendrocytes are visible (arrowheads). Note that these new oligodendrocytes were closely associated with myelin profiles.
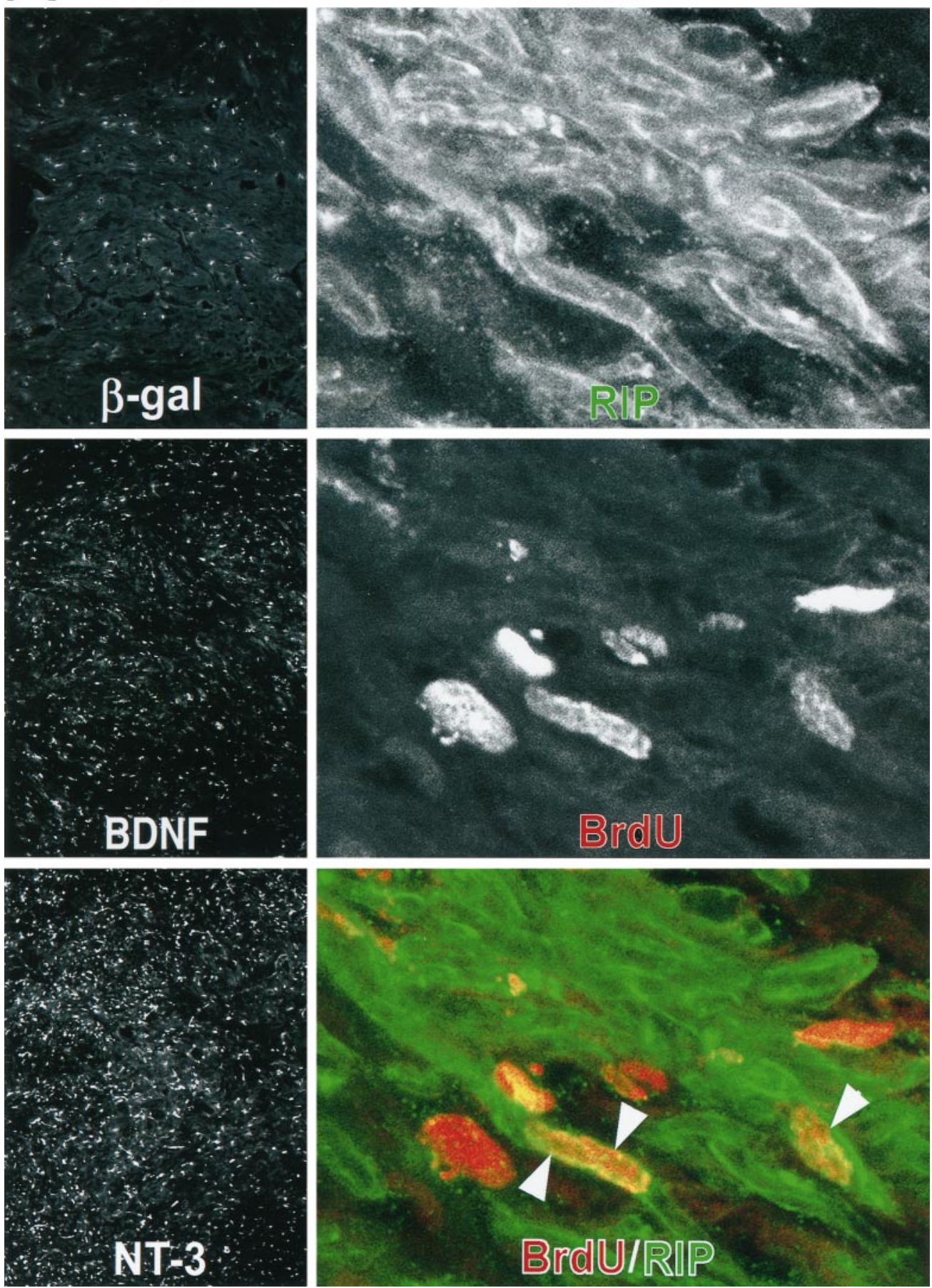

may prevent oligodendrocyte precursor differentiation and can induce dedifferentiation of mature oligodendrocytes (Fressinaud et al., 1995; Engel and Wolswijk, 1996; McMorris and McKinnon, 1996). A recent report by Bansal and Pfeiffer (1997) also suggests that bFGF may actually convert mature oligodendrocytes into a novel phenotype that is similar but not identical to the immature progenitor-like state. Thus, bFGF could potentially reduce oligodendrocyte myelination in the adult CNS by converting mature oligodendrocytes into a nonmyelinating phenotype. The elevation of Schwann cells within bFGF grafts is intriguing and may be caused by either an opportunistic invasion by Schwann cells or an as yet unreported chemotropic action of FGF on these cells.

The augmented myelination and proliferation in NT-3 and BDNF grafts may have been caused by a direct action on the oligodendrocytes or their precursors. For instance, oligodendrocytes can express the high-affinity BDNF and NT-3 receptors trkB and trkC (Barres et al., 1994; Condorelli et al., 1995; Cohen et al., 1996; Kumar and de Vellis, 1996). In addition, in vitro studies have shown that NT-3 can directly enhance oligodendrocyte precursor proliferation and survival (Barres et al., 1993, 
A

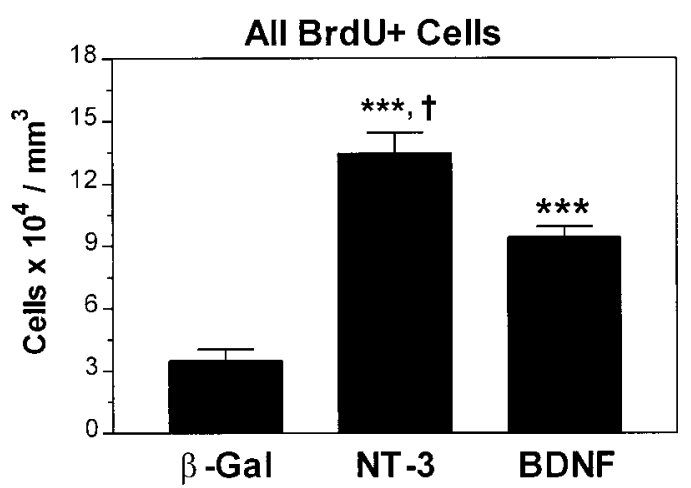

C

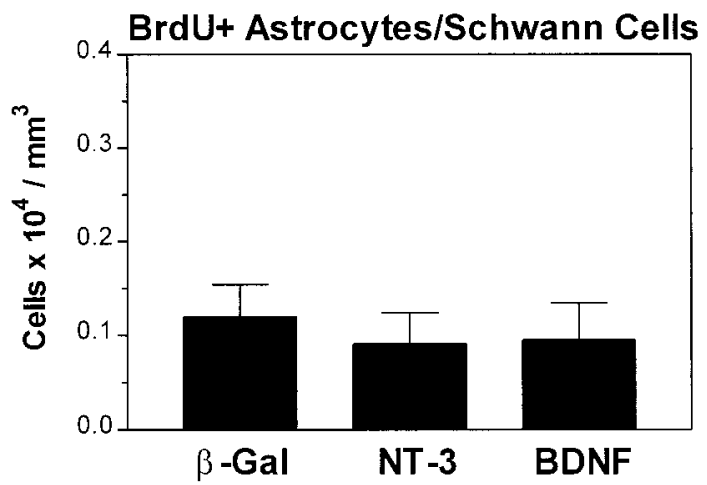

B

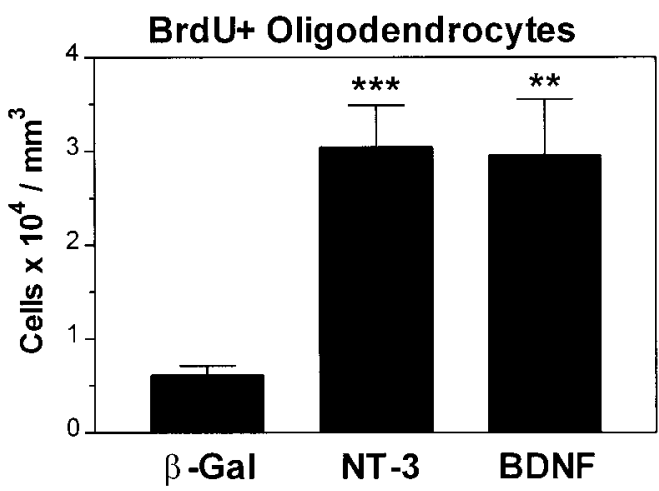

D

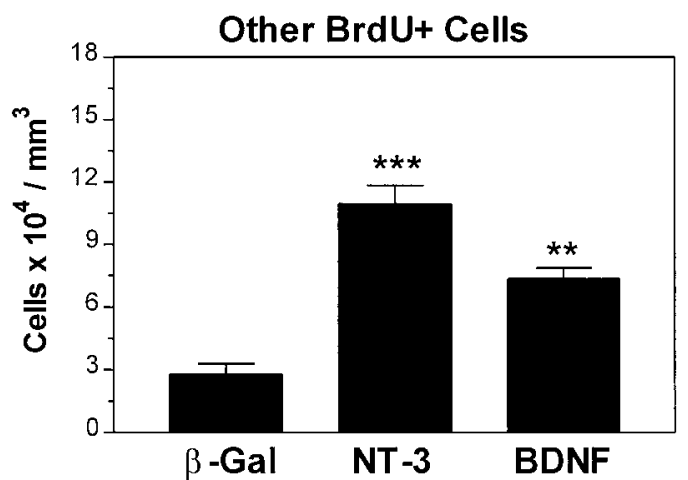

Figure 9. Quantification of mitotically active cells within NT-3, BDNF, and $\beta$-gal grafts. $A$, Quantification of proliferating cells (Fig. $8 A$ ) revealed that the density of BrdU-positive cells was significantly greater in NT-3 and BDNF grafts compared with control grafts $(* * * p<0.001)$. In addition, NT-3 grafts contained significantly more proliferating cells than BDNF grafts $\left({ }^{\dagger} p<0.001\right)$. $B$, Counts of RIP/BrdU double-labeled cells revealed that both NT-3 and BDNF grafts contained significantly more BrdU-positive oligodendrocytes than $\beta$-gal grafts $\left(* * p<0.01,{ }^{* * *} p<0.001\right)$, whereas the number of BrdU-labeled Schwann cells and astrocytes $(\operatorname{BrdU} / \mathrm{S} 100 \beta)$ was not different $(C)$. $D$, The number of unidentified BrdU-positive cells (not colabeled with RIP or S100 $\beta$ ) was significantly greater in NT-3 and BDNF grafts and may represent, at least in part, turnover of the fibroblast population. (Bars represent mean $\pm \mathrm{SEM} ; n=5$ for $\beta$-gal, NT-3; $n=4$ for BDNF).

1994). Compared with NT-3, less is known about BDNF-oligodendrocyte interactions. However, a study by Barres et al. (1993) showed that although BDNF alone had no effect on oligodendrocyte survival in culture, CNTF-induced survival was potentiated by the presence of BDNF. Thus BDNF may act directly on oligodendrocytes in vivo or may interact with other growth factors known to be present in the injured spinal cord, such as CNTF (Oyesiku et al., 1997).

An alternative hypothesis, however, is that the extensive neuritogenesis in NT-3 and BDNF grafts enhanced oligodendrocyte proliferation and myelination. For instance, Wood and Bunge (1986) reported that bare axons had a mitogenic effect on oligodendrocytes in culture. In our model, however, bare axons alone were not sufficient to induce significant cellular proliferation or myelinogenesis. This raises the question of whether fiber phenotype may direct new myelination. Although some differences were noted in phenotypic distribution within the grafts, i.e., ChAT fiber ingrowth, no known relationship between axonal phenotype and oligodendrocyte proliferation or myelination has been established. A more in-depth analysis of the association of new myelin and fiber type is needed to examine this hypothesis.
Evidence exists to suggest that the source of the new oligodendrocytes in the injured spinal cord was a population of endogenous progenitors. For instance, proliferative oligodendrocyte progenitors are known to be present in the adult CNS (Vick et al., 1992a). In addition, a recent report revealed that precursor cells in the subcortical white matter differentiated in response to chemical demyelination and subsequently remyelinated the lesion area (Gensert and Goldman, 1997). Although the suggestion has been made that mature oligodendrocytes can divide and contribute to remyelination (Wood and Bunge, 1991), the majority of research has focused on and supported the hypothesis that endogenous oligodendrocyte progenitors are present within the CNS, which can differentiate into mature cells capable of myelinating bare axons (Norton, 1996). Furthermore, it is well documented that growth factors can increase the proliferation and survival of oligodendrocyte progenitors (Barres et al., 1993, 1994; McMorris and McKinnon, 1996). Future studies will examine whether the new oligodendrocytes present in the NT-3 and BDNF grafts were derived from proliferating endogenous oligodendrocyte progenitors.

Because the fibroblasts were derived from a clonal population, 
the injected cell population did not contain oligodendrocytes or their precursors. Thus, it would appear that host oligodendrocytes (or their progenitors) migrated into the grafts to myelinate the ingrowing axons. Although theoretically some oligodendrocytes or their precursors could have become intermixed with the fibroblasts during the transplantation procedure, this probably would have occurred equally in all grafts. Although the current data do not contain any direct observations on oligodendrocyte migration, previous experimental evidence indicates that oligodendrocytes, and in particular their progenitors, can migrate in vivo. For instance, it is known that immature oligodendrocytes are highly motile during development (Small et al., 1987; Miller et al., 1997; Ono et al., 1997). In addition, previous transplantation studies using oligodendrocyte progenitors demonstrated the ability of these cells to migrate through host CNS tissue, especially through regions of marked pathology (Vignais et al., 1993; Warrington et al., 1993; Lachapelle et al., 1994; Franklin et al., 1996; Osterhout et al., 1997; Tourbah et al., 1997). A recent report by Franklin et al. (1997) suggested that the distance endogenous cells can migrate to repair a demyelinated zone is limited to 2 $\mathrm{mm}$. In our model, the maximal distance from the edge of the white matter to the center of the graft is $\sim 1.2 \mathrm{~mm}$ and thus within the range observed by Franklin and colleagues (1997). In addition, a study by Milner et al. (1996) examining the effect of extracellular matrix molecules on the migratory rate of oligodendrocyte precursors revealed that fibronectin increased the rate of migration. Because a major product of fibroblasts is fibronectin, the grafts should provide an environment that is conducive for progenitor migration. Although a recent report by Gensert and Goldman (1997) showed that endogenous proliferating precursors did not migrate into a nearby demyelinated region, it is possible that migration in our model was promoted by NT-3 and BDNF, because it is known that other growth factors can promote migration of oligodendrocyte precursors (Armstrong et al., 1990; Milner et al., 1997).

In summary, the present study reveals for the first time that the presence of NT-3 or BDNF in the injured spinal cord induced the formation of new oligodendrocytes. Furthermore, grafts producing these neurotrophins promoted neuritogenesis and myelination of the ingrowing axons. Because demyelination is a consistent characteristic of SCI, it will be important to determine whether host myelination can also be altered by these neurotrophins. Additionally, these techniques may be applicable to demyelinating diseases such as multiple sclerosis, in which relatively quiescent oligodendrocyte progenitors are known to exist within demyelinated plaques (Wolswijk, 1998).

\section{REFERENCES}

Anderson T, Stokes BT (1992) Experimental models for spinal cord injury research: physical and physiological considerations. J Neurotrauma 9[Suppl 1]:S135-S142.

Archelos JJ, Roggenbuck K, Schneider-Schaulies J, Linington C, Toyka KV, Hartung H-P (1993) Production and characterization of monoclonal antibodies to the extracellular domain of P0. J Neurosci Res $35: 46-53$.

Armstrong RC, Harvath L, Dubois-Dalcq ME (1990) Type 1 astrocytes and oligodendrocyte-type 2 astrocyte glial progenitors migrate toward distinct molecules. J Neurosci Res 27:400-407.

Balentine JD (1978) Pathology of experimental spinal cord trauma. II. Ultrastructure of axons and myelin. Lab Invest 39:254-266.

Bansal R, Pfeiffer SE (1997) FGF-2 converts mature oligodendrocytes to a novel phenotype. J Neurosci Res 50:215-228.

Barres BA, Schmid R, Sendnter M, Raff MC (1993) Multiple extracellular signals are required for long-term oligodendrocyte survival. Development 118:283-295.
Barres BA, Raff MC, Gaese F, Bartke I, Dechant G, Barde YA (1994) A crucial role for neurotrophin-3 in oligodendrocyte development. Nature 367:371-375.

Barres BA, Burne JF, Holtmann B, Thoenen H, Sendnter M, Raff MC (1996) Ciliary neurotrophic factor enhances the rate of oligodendrocyte generation. Mol Cell Neurosci 8:146-156.

Beattie MS, Bresnahan JC, Komon J, Tovar CA, Van Meter M, Anderson DK, Faden AI, Hsu CY, Noble LJ, Salzman S, Young W (1997) Endogenous repair after spinal cord contusion injuries in the rat. Exp Neurol 148:453-463.

Blight AR (1983) Cellular morphology of chronic spinal cord injury in the cat: analysis of myelinated axons by line-sampling. Neuroscience 10:521-543.

Bresnahan JC (1976) An electron-microscopic analysis of axonal alterations following blunt contusion of the spinal cord of the rhesus monkey (Macaca Mulatta). J Neurol Sci 37:59-82.

Cheng H, Cao YH, Olson L (1996) Spinal cord repair in adult paraplegic rats: partial restoration of hind limb function. Science 273:510-513.

Cohen RI, Marmur R, Norton WT, Mehler MF, Kessler JA (1996) Nerve growth factor and neurotrophin-3 differentially regulate the proliferation and survival of developing rat brain oligodendrocytes. J Neurosci 16:6433-6442.

Condorelli DF, Salin T, Dell' Albani P, Mudo G, Corsaro M, Timmusk T, Metsis M, Belluardo N (1995) Neurotrophins and their trk receptors in cultured cells of the glial lineage and in white matter of the central nervous system. J Mol Neurosci 6:237-248.

Crowe MJ, Bresnahan JC, Shuman SL, Masters JN, Beattie MS (1997) Apoptosis and delayed degeneration after spinal cord injury in rats and monkeys. Nature Med 3:73-76.

D’Souza SD, Alinauskas KA, Antel JP (1996) Ciliary neurotrophic factor selectively protects human oligodendrocytes from tumor necrosis factor-mediated injury. J Neurosci Res 43:289-298.

Engel G, Wolswijk G (1996) Oligodendrocyte-type-2 astrocyte (O-2A) progenitor cells derived from adult rat spinal cord: in vitro characteristics and response to PDGF, bFGF and NT-3. Glia 16:16-26.

Franklin RJM, Bayley SA, Blakemore WF (1996) Transplanted CG4 cells (an oligodendrocyte progenitor cell line) survive, migrate, and contribute to repair of areas of demyelination in X-irradiated and damaged spinal cord but not in normal spinal cord. Exp Neurol 137:263-276.

Franklin RJM, Gilson JM, Blakemore WF (1997) Local recruitment of remyelinating cells in the repair of demyelination in the central nervous system. J Neurosci Res 50:337-344.

Fressinaud C, Vallet JM, Labourdette G (1995) Basic fibroblast growth factor down-regulates myelin basic protein gene expression and alters myelin compaction of mature oligodendrocytes in vitro. J Neurosci Res 40:285-293.

Friedman B, Hockfield S, Black JA, Woodruff KA, Waxman SG (1989) In situ demonstration of mature oligodendrocytes and their processes: an immunocytochemical study with a new monoclonal antibody, Rip. Glia 2:380-390.

Gensert JM, Goldman JE (1997) Endogenous progenitors remyelinate demyelinated axons in the adult CNS. Neuron 19:197-203.

Gledhill RF, Harrison BM, McDonald WI (1973) Demyelination and remyelination after acute spinal cord compression. Exp Neurol 38:472-487.

Grill R, Murai K, Blesch A, Gage FH, Tuszynski MH (1997) Cellular delivery of neurotrophin-3 promotes corticospinal axonal growth and partial functional recovery after spinal cord injury. J Neurosci 17:5560-5572.

Gundersen HJ, Bagger P, Bendtsen TF, Evans SM, Korbo L, Marcussen N, Moller A, Nielsen K, Nyengaard JR, Pakkenberg B, Sorensen FB, Vesterby A, West MJ (1988) The new stereological tools: disector, fractionator, nucleator and point sampled intercepts and their use in pathological research and diagnosis. APMIS 96:857-881.

Guth L, Barrett CP, Donati EJ, Anderson FD, Smith MV, Lifson M (1985) Essentiality of a specific cellular terrain for growth of axons into a spinal cord lesion. Exp Neurol 88:1-12.

Horner PJ, Power AE, Kempermann G, Kuhn HG, Winkler J, Palmer TD, Gage FH (1997) Progenitor proliferation in the normal, epidermal-, fibroblast- or nerve growth factor-treated adult rat spinal cord: opportunities for spinal injury repair? Fifteenth Annual National Neurotrauma Meeting. J Neurotrauma 14:804.

Jakeman LB, Wei P, Guan Z, Stokes BT (1998) Brain-derived neuro- 
trophic factor infusion affects hindlimb activity after spinal cord injury in rats. Exp Neurol, in press.

Kakulas BA (1984) Pathology of spinal injuries. CNS Trauma $1: 117-129$.

Kawaja MD, Gage FH (1992) Morphological and neurochemical features of cultured primary skin fibroblasts of Fischer 344 rats following striatal implantation. J Comp Neurol 317:102-116.

Kishino A, Ishige Y, Tatsuno T, Nakayama C, Noguchi H (1997) BDNF prevents and reverses adult rat motor neuron degeneration and induces axonal outgrowth. Exp Neurol 144:273-286.

Kumar S, de Vellis J (1996) Neurotrophin activates signal transduction in oligodendroglial cells: expression of functional trkC receptor isoforms. J Neurosci Res 44:490-498.

Lachapelle F, Duhamel-Clerin ED, Gansmüller A, Baron-Van Evercooren A, Villarroya H, Gumpel M (1994) Transplanted transgenically marked oligodendrocytes survive, migrate and myelinate in the normal mouse brain as they do in the shiverer mouse brain. Eur J Neurosci 6:814-824.

Li GL, Brodin G, Farooque M, Funa K, Holtz A, Wang WL, Olsson Y (1996) Apoptosis and expression of Bcl-2 after compression trauma to rat spinal cord. J Neuropathol Exp Neurol 55:280-289.

Louis JC, Magal E, Takayama S, Varon S (1993) CNTF protection of oligodendrocytes against natural and tumor necrosis factor-induced death. Science 259:689-692.

McMorris FA, McKinnon RD (1996) Regulation of oligodendrocyte development and CNS myelination by growth factors: prospects for therapy of demyelinating disease. Brain Pathol 6:313-329.

Miller RH, Payne J, Milner L, Zhang H, Orantas DM (1997) Spinal cord oligodendrocytes develop from a limited number of migratory, highly proliferative precursors. J Neurosci Res 50:157-168.

Milner R, Edwards G, Streuli C, ffrench-Constant C (1996) A role in migration for the $\alpha \mathrm{v} \beta 1$ integrin expressed on oligodendrocyte precursors. J Neurosci 16:7240-7252.

Milner R, Anderson HJ, Rippon RF, McKay JS, Franklin RJM, Marchionni MA, Reynolds R, ffrench-Constant C (1997) Contrasting effects of mitogenic growth factors on oligodendrocyte precursor cell migration. Glia 19:85-90.

Norton WT (1996) Do oligodendrocytes divide? Neurochem Res 21:495-503.

Novikov L, Novikova L, Kellerth J-O (1997) Brain-derived neurotrophic factor promotes axonal regeneration and long-term survival of adult rat spinal motoneurons in vivo. Neuroscience 79:766-774.

Ono K, Yasui Y, Rutishauser U, Miller RM (1997) Focal ventricular origin and migration of oligodendrocyte precursors into the chick optic nerve. Neuron 19:283-292.

Osterhout DJ, Ebner S, Xu J, Ornitz DM, Zazanis GA, McKinnon RD (1997) Transplanted oligodendrocyte progenitor cells expressing a dominant-negative FGF receptor transgene fail to migrate in vivo. J Neurosci 17:9122-9132.

Oyesiku NM, Wilcox JN, Wigston DJ (1997) Changes in expression of ciliary neurotrophic factor (CNTF) and CNTF-receptor alpha after spinal cord injury. J Neurobiol 32:251-261.

Popovich PG, Yu JY, Whitacre CC (1997) Spinal cord neuropathology in rat experimental autoimmune encephalomyelitis: modulation by oral administration of myelin basic protein. J Neuropathol Exp Neurol 56:1323-1338.

Senut MC, Tuszynski MH, Raymon HK, Suhr ST, Liou NH, Jones KR, Reichardt LF, Gage FH (1995) Regional differences in responsiveness of adult CNS axons to grafts of cells expressing human neurotrophin 3. Exp Neurol 135:36-55.

Small RK, Riddle P, Noble M (1987) Evidence for migration of oligodendrocyte-type-2 astrocyte progenitor cells into the developing rat optic nerve. Nature 328:155-157.

Stokes BT, Noyes DH, Behrmann DL (1992) An electromechanical spinal injury device with dynamic sensitivity. J Neurotrauma 9:187-195.

Stokes BT, Horner PJ, Akino M (1995) Spinal cord injury modeling and functional assessment. In: Central nervous system trauma: research techniques (Ohnishi ST, Ohnishi T, eds), pp 281-295. New York: CRC.

Tourbah A, Linnington C, Bachelin C, Avellana-Adalid V, Wekerle H, Baron-Van Evercooren A (1997) Inflammation promotes survival and migration of the CG4 oligodendrocyte progenitors transplanted in the spinal cord of both inflammatory and demyelinated EAE rats. J Neurosci Res 50:853-861.

Vick RS, Collins JM, DeVries GH (1992a) Cell cycle and proliferation dynamics of adult rat oligodendrocytes. J Neurosci Res 33:75-81.

Vick RS, Neuberger TJ, DeVries GH (1992b) Role of adult oligodendrocytes in remyelination after neural injury. J Neurotrauma 9[Suppl 1]:S93-S103.

Vignais L, Nait Oumesmar B, Mellouk F, Gout O, Labourdette G, Baron-Van Evercooren A, Gumpel M (1993) Migration of oligodendrocytes. Transplantation of oligodendrocyte precursors in the adult demyelinated spinal cord: migration and remyelination. Int $\mathrm{J}$ Dev Neurosci 11:603-612.

Warrington AE, Barbarese E, Pfeiffer SE (1993) Differential myelinogenic capacity of specific developmental stages of the oligodendrocyte lineage upon transplantation into hypomyelinating hosts. J Neurosci Res 34:1-13.

Wolswijk G (1998) Chronic stage multiple sclerosis lesions contain a relatively quiescent population of oligodendrocyte precursor cells. J Neurosci 18:601-609.

Wood PM, Bunge RP (1986) Evidence that axons are mitogenic for oligodendrocytes isolated from adult animals. Nature 320:756-758.

Wood PM, Bunge RP (1991) The origin of remyelinating cells in the adult central nervous system: the role of the mature oligodendrocyte. Glia 4:225-232.

Xu XM, Guenard V, Kleitman N, Aebischer P, Bunge MB (1995) A combination of BDNF and NT-3 promotes supraspinal axonal regeneration into Schwann cell grafts in adult rat thoracic spinal cord. Exp Neurol 134:261-272. 